\title{
Anti-Epidermal Growth Factor Receptor Antibody Readministration in Chemorefractory Metastatic Colorectal Cancer
}

\author{
TATSUHIRO KAJITANI ${ }^{1,2}$, AKITAKA MAKIYAMA ${ }^{1,3}$, SHUJI ARITA $^{1,4}$, HOZUMI SHIMOKAWA $^{1,2}$, \\ HISANOBU ODA $^{1,5}$, TSUYOSHI SHIRAKAWA ${ }^{1,6}$, EISHI BABA ${ }^{4}$ and TAITO ESAKI ${ }^{1}$ \\ ${ }^{1}$ Department of Gastrointestinal and Medical Oncology, National Kyushu Cancer Center, Fukuoka, Japan; \\ ${ }^{2}$ Department of Medical Oncology, Clinical Research Institute, \\ National Hospital Organization Kyushu Medical Center, Fukuoka, Japan; \\ ${ }^{3}$ Department of Hematology and Oncology, \\ Japan Community Healthcare Organization Kyushu Hospital, Kitakyushu, Japan; \\ ${ }^{4}$ Department of Comprehensive Clinical Oncology, Faculty of Medical Sciences, \\ Kyushu University, Fukuoka, Japan; \\ ${ }^{5}$ Department of Oncology, Saiseikai Fukuoka General Hospital, Fukuoka, Japan; \\ ${ }^{6}$ Department of Oncology, Miyazaki Prefectural Miyazaki Hospital, Miyazaki, Japan
}

\begin{abstract}
Background/Aim: Readministration of antiepidermal growth factor receptor (EGFR) antibody for metastatic colorectal cancer $(m C R C)$ after disease progression remains to be determined. Patients and Methods: Readministration of anti-EGFR antibody in $m C R C$ patients previously refractory to anti-EGFR antibody was prospectively observed. Results: A total of thirteen patients with a median age of 60-years old and an Eastern Cooperative Oncology Group (ECOG) performance status 0 or 1 , were enrolled. The median number of previous chemotherapies was 3 (range 2-5). Prior anti-EGFR antibody in combination with cytotoxic drugs was administered in 12 patients. Anti-EGFR antibody readministration regimens were cetuximab/panitumumab plus capecitabine/S-1 (seven patients), panitumumab plus FOLFOX (three patients), cetuximab plus irinotecan (two patients), and panitumumab monotherapy (one patient). Seven patients showed stable disease following readministration and six patients showed progressive disease. The median overall survival (OS) following readministration was 228 days and the median PFS was 102 days. Patients with intervals longer than 90 days
\end{abstract}

Correspondence to: Prof. Taito Esaki, Department of Gastrointestinal and Medical Oncology, National Kyushu Cancer Center, 3-1-1, Notame, Minami-ku, Fukuoka 811-1395, Japan. Tel: +81 925413231, Fax: +81 925428503, e-mail: tesaki@nk-cc.go.jp

Key Words: Colorectal cancer, chemotherapy, anti-epidermal growth factor receptor antibody, readministration. between anti-EGFR therapies exhibited more favorable survival than those with intervals shorter than 90 days. Switching of anti-EGFR antibody between treatments was observed to contribute survival. Conclusion: Anti-EGFR antibody readministration could show a modest survival benefit in $m C R C$ patients, with the length of therapy interval and switching of antibody being important contributory factors.

Colorectal cancer is the second most frequent cause of cancer death worldwide (1) and the second cause of cancer death in Japan (2). While surgery is generally performed for local disease, a proportion of colorectal cancer patients are diagnosed as having an inoperative state, such as those possessing distant metastasis. Systemic chemotherapy is the standard therapy for these unresectable or metastatic colorectal cancer (mCRC) patients. Cytotoxic drugs employed for mCRC include the combination of fluoropyrimidine with either oxaliplatin (FOLFOX) or irinotecan (FOLFIRI). In first-line or second-line treatment, the addition of molecularly-targeted agents to cytotoxic drugs has been commonly utilized; antibodies against the vascular endothelial growth factor (anti-VEGF-A; bevacizumab), and the VEGF receptor (anti-VEGFR; ramucirumab) for example, are reported to provide survival benefit for mCRC patients $(3,4)$. In addition, the epidermal growth factor receptor (EGFR) antibodies, cetuximab and panitumumab, have shown efficacy in mCRC patients wildtype for the RAS gene, both as monotherapy and in combination with cytotoxic drugs (5-9). First-line treatment 
with anti-EGFR antibody in combination with chemotherapy has been reported to achieve around 10 months of progression-free survival (PFS) $(5,6)$.

In cases where first-line chemotherapy becomes ineffective or intolerable, other drugs must generally be used for the treatment of the advanced tumor. On the other hand, the human epidermal growth factor receptor 2 (HER2) antibody, trastuzumab, has been continuously administered in HER2-positive metastatic breast cancer patients even after the failure of prior therapy with this antibody. This approach is based upon a clinical trial that showed that the combination of capecitabine and trastuzumab was more beneficial than capecitabine monotherapy for advanced breast cancer patients resistant to trastuzumab (10). Similarly, in the treatment of mCRC, a prospective study has demonstrated that the continuation of a bevacizumab-based therapy following failure of prior bevacizumab-containing first-line chemotherapy, was effective (11). In that trial, mCRC patients with disease progression up to 3 months after discontinuing first-line bevacizumab plus chemotherapy, were randomly assigned to second-line chemotherapy with or without bevacizumab. The median overall survival (OS) was 11.2 months for bevacizumab plus chemotherapy, compared to 9.8 months for chemotherapy alone (11). Therefore, certain molecularly-targeted agents may continue to show a survival benefit in ongoing therapy, even after the failure of first administration of the drug. However, the effectiveness of continuous use or readministration of the anti-EGFR antibody following prior treatment failure in $\mathrm{mCRC}$ has not been well examined.

Several mechanisms of acquired resistance of anti-EGFR therapy in $\mathrm{mCRC}$ have been proposed, including not only the genetic alteration of key tumor genes, but also the clonal selection of resistant cells during anti-EGFR therapy (12). The latter mechanism raises the possibility that an antibody-free interval following initial anti-EGFR therapy, might provide a chance to regain tumor sensitivity to this antibody. Such an approach has been used in several clinical studies, but the efficacy and safety profile of anti-EGFR readministration has not been properly assessed. In addition, the relationship between the length of the discontinuation period or switching administration of antibody and the efficacy of anti-EGFR readministration has not been examined. The present study was therefore conducted to explore the safety and efficacy of anti-EGFR antibody readministration for the treatment of $\mathrm{mCRC}$ in clinical practice.

\section{Patients and Methods}

Patients. The present prospective observational study examined the readministration of anti-EGFR antibody in $\mathrm{mCRC}$ patients resistant to standard therapy, including fluoropyrimidine, oxaliplatin, irinotecan, bevacizumab, and the anti-EGFR antibodies cetuximab or panitumumab. Patients were registered between 1st May 2010 and 31st January 2013 in the Department of Oncology and Gastroenterology, National Organization Kyushu Cancer Center, Fukuoka, Japan. Patients were between 20 and 75 years old, with each having an Eastern Cooperative Oncology Group (ECOG) performance status (PS) of 0 to 2 , and a histologically confirmed KRAS wildtype adenocarcinoma of the colon and rectum with measurable lesions according to the Response Evaluation Criteria in Solid Tumors guideline (RECIST ver. 1.1) (13). Life expectancy for each of these patients was $>3$ months.

Resistance to standard therapy was defined as disease progression after at least 4 weeks of treatments with fluoropyrimidine, oxaliplatin, irinotecan, or bevacizumab. Resistance to anti-EGFR therapy was defined as confirmed disease progression following treatment with an anti-EGFR antibody for at least 4 weeks. Additional criteria for inclusion were as follows: white blood cell count $\geq 3,000 / \mathrm{mm}^{3}$ and $\leq 12,000 / \mathrm{mm}^{3}$, absolute neutrophil count $\geq 1,500 / \mathrm{mm}^{3}$, platelet count $\geq 100,000 / \mathrm{mm}^{3}$, and hemoglobin $\geq 9.0$ $\mathrm{g} / \mathrm{dl}$. Major organ function was assessed to ensure that normal electrocardiogram, hepatic function (total bilirubin $\leq 1.5 \mathrm{mg} / \mathrm{dl}$, aspartate aminotransferase and alanine aminotransferase $\leq 100 \mathrm{IU} / 1$ or 150 with hepatic metastasis) and renal function (serum creatinine $\leq 1.5 \mathrm{mg} / \mathrm{dl}$ ) were maintained. Patients with complications of uncontrollable diabetes mellitus, critical infection, cardiac infarction, large pleural effusion and ascites, interstitial pneumonia, and intestinal obstruction, were excluded. This study was approved by the ethics committee of the National Kyushu Cancer Center, and performed according to the guidelines for biomedical research in the Declaration of Helsinki. All patients provided written informed consent for their participation in this prospective observational study.

Clinical variables assessed. Medical information from each patient was examined using electronic records. Items surveyed included age, gender, ECOG PS, pathohistological diagnosis, KRAS mutational status, metastatic and recurrent sites, and disease status. Data relating to previous chemotherapies and anti-EGFR therapy were also assessed, including the content of the chemotherapy, tumor response, progression-free survival (PFS) and overall survival (OS). Therapy-related toxicities were assessed according to the Common Terminology Criteria for Adverse Events (CTC-AE) version 4.0 (14), and toxicities with CTC-AE Grade 3 or worse were surveyed.

Statistical analysis. PFS was defined as the period from the initiation of therapy to the day of tumor progression or death from any cause. OS was defined as the period from initiation of therapy to the day of death from any cause. PFS and OS were estimated using the Kaplan-Meier method, with the log-rank test used to compare survival of the two patient groups. Analyses were twosided and used an alpha type I error of 5\%. All statistical procedures were performed using SPSS (IBM, Armonk, NY, USA).

\section{Results}

Patient background. From May 2010 to January 2013, we administered anti-EGFR antibody to $13 \mathrm{mCRC}$ patients that were considered resistant to different combinations of fluorinated pyrimidine, oxaliplatin, irinotecan, bevacizumab and anti-EGFR antibody. Their median age was 60 years 
Table I. Patient characteristics and treatments.

\begin{tabular}{|c|c|c|}
\hline Clinical features & Number of patients & $\%$ \\
\hline Age, year (range) & \multicolumn{2}{|c|}{$60(27-75)$} \\
\hline Gender & 9 & 69 \\
\hline Male & 4 & 31 \\
\hline \multicolumn{3}{|l|}{ Female } \\
\hline \multicolumn{3}{|l|}{ ECOG performance status } \\
\hline 0 & 3 & 23 \\
\hline 1 & 10 & 77 \\
\hline \multicolumn{3}{|l|}{ Primary tumor site } \\
\hline Colon & 8 & 62 \\
\hline Rectum & 5 & 38 \\
\hline Number of metastatic sites (range) & \multicolumn{2}{|c|}{$2(1-4)$} \\
\hline \multicolumn{3}{|l|}{ Metastatic site } \\
\hline Liver & 8 & 62 \\
\hline Lung & 8 & 62 \\
\hline Lymph node & 4 & 31 \\
\hline Number of prior regimens (range) & \multicolumn{2}{|c|}{$3(2-5)$} \\
\hline Time between prior and readministration anti-EGFR antibody, days (range) & \multicolumn{2}{|c|}{$26(7-301)$} \\
\hline \multicolumn{3}{|l|}{ Prior anti-EGFR therapy regimen } \\
\hline Cetuximab + irinotecan & 10 & 77 \\
\hline Cetuximab + FOLFOX & 1 & 8 \\
\hline Panitumumab + FOLFOX & 1 & 8 \\
\hline Panitumumab monotherapy & 1 & 8 \\
\hline \multicolumn{3}{|l|}{ Readministration anti-EGFR therapy regimen } \\
\hline Cetuximab + capecitabine/S-1 & 4 & 31 \\
\hline Cetuximab + irinotecan & 2 & 15 \\
\hline Panitumumab + FOLFOX & 2 & 15 \\
\hline Panitumumab + fluorouracil/S-1 & 4 & 31 \\
\hline Panitumumab monotherapy & 1 & 8 \\
\hline
\end{tabular}

ECOG: Eastern Cooperative Oncology Group; EGFR: Epidermal growth factor receptor; FOLFOX: leucovorin, fluorouracil, oxaliplatin; FOLFIRI: leucovorin, fluorouracil, irinotecan; S-1: tegafur, gimeracil, oteracil.

(range, 27-75), and the population included nine men (69\%) and four women $(31 \%)$ (Table I). ECOG PS was 0 in three patients $(23 \%)$ and 1 in ten patients $(77 \%)$. The primary tumor was located in the colon in eight patients $(62 \%)$ and the rectum in five patients $(38 \%)$. Tumors in all patients were diagnosed as adenocarcinomas with wildtype KRAS gene by histological examination. The median number of metastatic sites was two per patient (range, 1-4), which included the liver in eight patients $(62 \%)$, the lungs in eight patients $(62 \%)$, and the lymph nodes in four patients $(31 \%)$.

Treatments. All patients had received prior treatments (Table II), of which the median number of regimens was 3 (range, 2-5). Prior chemotherapy regimens that contained anti-EGFR antibody were cetuximab plus irinotecan in ten patients $(77 \%)$, cetuximab plus FOLFOX in one patient $(8 \%)$, panitumumab plus FOLFOX in one patient $(8 \%)$, and panitumumab monotherapy in one patient $(8 \%)$. In the readministration of anti-EGFR antibody therapy after a discontinuation period, four patients were treated with cetuximab plus oral fluoropyrimidine such as capecitabine or S-1 in four patients $(31 \%)$, cetuximab plus irinotecan in two patients $(15 \%)$, panitumumab plus FOLFOX in two patients (15\%), panitumumab plus fluorouracil or S-1 in four patients (31\%), and panitumumab monotherapy in one patient $(8 \%)$ (Table II). The median interval between the termination of the prior anti-EGFR therapy and the initiation of readministered anti-EGFR therapy was 26 days (range=7-301).

Efficacy. In the prior chemotherapy with anti-EGFR antibody, partial response was observed in four patients $(31 \%)$, stable disease in seven patients $(54 \%)$, and progressive disease in two patients (15\%) (Table II). Following anti-EGFR antibody readministration, seven patients $(54 \%)$ demonstrated stable disease and six patients $(46 \%)$ had progressive disease (Table II). No patients had complete response or partial response. Five patients had tumor shrinkage within stable disease. Overall, patients that did not show clinical benefit from prior anti-EGFR antibody did not show evidence of clinical benefit from its 
Table II. Treatment of each patient.

\begin{tabular}{lccccc}
\hline Patient & $\begin{array}{c}\text { Prior anti-EGFR } \\
\text { regimen (Number } \\
\text { of treatment line) }\end{array}$ & $\begin{array}{c}\text { Tumor shrinkage } \\
\text { in prior therapy } \\
(\%) *\end{array}$ & $\begin{array}{c}\text { Interval between } \\
\text { prior therapy and } \\
\text { readministration (days) }\end{array}$ & $\begin{array}{c}\text { Readministration } \\
\text { of anti-EGFR regimen } \\
\text { (Number of treatment line) }\end{array}$ & $\begin{array}{c}\text { Tumor shrinkage } \\
\text { in readministration } \\
(\%) *\end{array}$ \\
\hline 1 & C + FOLFOX (1) & -37 & 84 & C + irinotecan (3) & 29 \\
2 & P monotherapy (3) & 7 & 182 & C + irinotecan (4) & 22 \\
3 & C + irinotecan (3) & 29 & 21 & P + FOLFOX (5) & 21 \\
4 & C + irinotecan (4) & -34 & 13 & P + fluorouracil (5) & 18 \\
5 & C + irinotecan (3) & 28 & 7 & C + capecitabine (4) & 16 \\
6 & C + irinotecan (3) & -28 & 7 & C + capecitabine (4) & P + S-1 (4) \\
7 & C + irinotecan (3) & 10 & 73 & C + capecitabine (5) & P + S-1 (5) \\
8 & C + irinotecan (3) & -1 & 60 & P monotherapy (4) & -2 \\
9 & C + irinotecan (3) & -56 & 21 & P + S-1 (6) & -3 \\
10 & C + irinotecan (3) & 5 & 129 & P + FOLFOX (6) & -16 \\
11 & C + irinotecan (4) & -27 & 26 & C + S-1 (4) & -17 \\
12 & C + irinotecan (5) & -20 & 301 & -20.5 \\
13 & P + FOLFOX (1) & -46 & & & -2 \\
\hline
\end{tabular}

*Negative values indicate decrease of tumor size. EGFR: epidermal growth factor receptor; C: cetuximab; P: panitumumab; FOLFOX: leucovorin, fluorouracil, oxaliplatin; S-1: tegafur, gimeracil, oteracil.

readministration either. The median PFS and the median OS were 102 days and 228 days, respectively (Figure 1).

Safety. During readministration of anti-EGFR therapy, adverse events $\geq$ Grade 3 (CTCAE version 4.0) of thrombocytopenia, paronychia, peripheral sensory neuropathy and ileus were each observed in a single patient (Table III). Although rash acneiform and anemia occurred in almost all patients to varying degrees as expected (12 patients, $92 \%$ ), no severe disease was observed (Table III).

Subgroup analysis. To explore the impact of prior anti-EGFR responsiveness on patient outcome following the readministration of anti-EGFR antibody, we compared the survival of two patient groups, seven patients who showed tumor shrinkage of $\geq 20 \%$ during the initial therapy, and six patients with tumor shrinkage $<20 \%$ during initial therapy (Figure 2). The median PFS was 101 and 105 days, respectively ( $p=0.782$ ), while the median OS was 209 and 235 days, respectively $(p=0.579)$. This data thus suggested no significant relationship in terms of prior responsiveness to EGFR antibody therapy and patient survival following therapy readministration.

To confirm this observation, we performed a waterfall plot analysis of tumor growth recorded during the different phases of therapy in these patients (Figure 3). Of the five patients that demonstrated tumor growth during initial anti-EGFR therapy, four of these patients similarly showed no sign of tumor shrinkage following readministration. In contrast, three out of the eight patients that showed a reduction in tumor burden during initial therapy, also showed tumor shrinkage during therapy readministration (Figure 3). These findings suggested that patients with primary resistance to anti-EGFR antibody therapy tend to maintain this resistance during subsequent therapy. We then analyzed whether the interval between the termination of the initial anti-EGFR therapy and subsequent readministration with anti-EGFR antibody affected patient outcome (Figure 4). In three patients, antiEGFR therapy readministration was performed after an interval of $\geq 90$ days. Comparing the survival of these patients with the 10 patients who were readministered with anti-EGFR antibody $<90$ days after cessation of prior therapy, those with a longer therapy-free interval showed a trend towards more favorable clinical outcome than those with a shorter therapyfree interval (Figure 4). The median PFS of these groups was 194 and 100 days, respectively $(p=0.124)$, while OS was 331 and 211 days respectively $(p=0.397)$.

Since anti-EGFR antibody was switched from one to the other drug in the readministration for the three patients that showed tumor shrinkage (Figure 3), we thus compared between the outcome of patient groups, the switched group and the non-switched group (Figure 5). The switched group included patients treated with cetuximab in the prior therapy and panitumumab in the readministration, and vice versa. The non-switched group was treated with the same antiEGFR antibody in the readministration as in the prior therapy. The switched group seemed to exhibit longer PFS and OS than the non-switched group (median PFS; 116 days versus 98 days, median OS; 276 days versus 135 days), but not statistically significant ( $p=0.166$ in PFS, $p=0.072$ in OS). These data suggested that switching anti-EGFR antibody might contribute to favorable clinical outcome. 
A

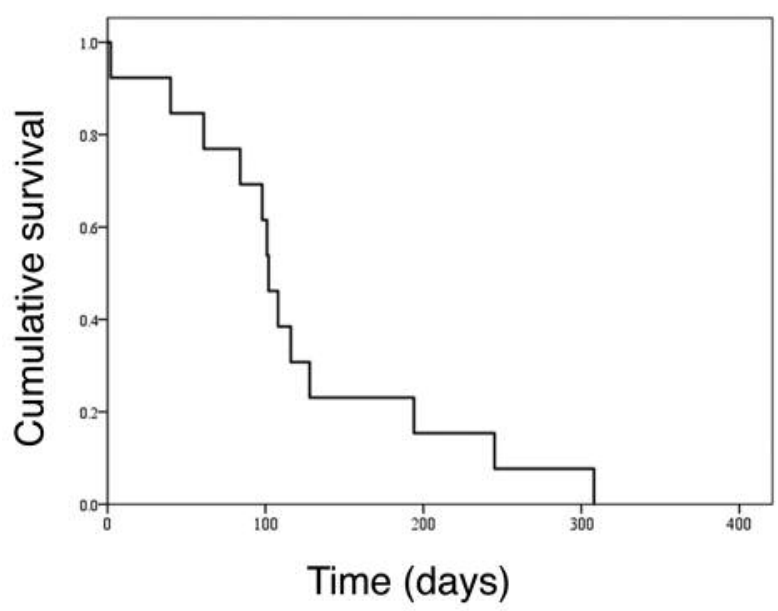

B

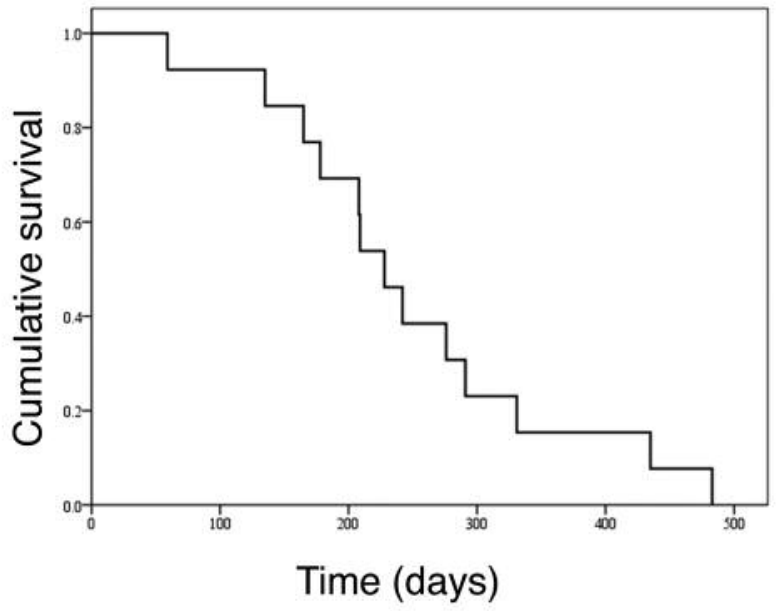

Figure 1. Kaplan-Meier curve analysis. (A) Progression free survival, and (B) overall survival (OS) outcomes for all patients ( $n=13)$.

A

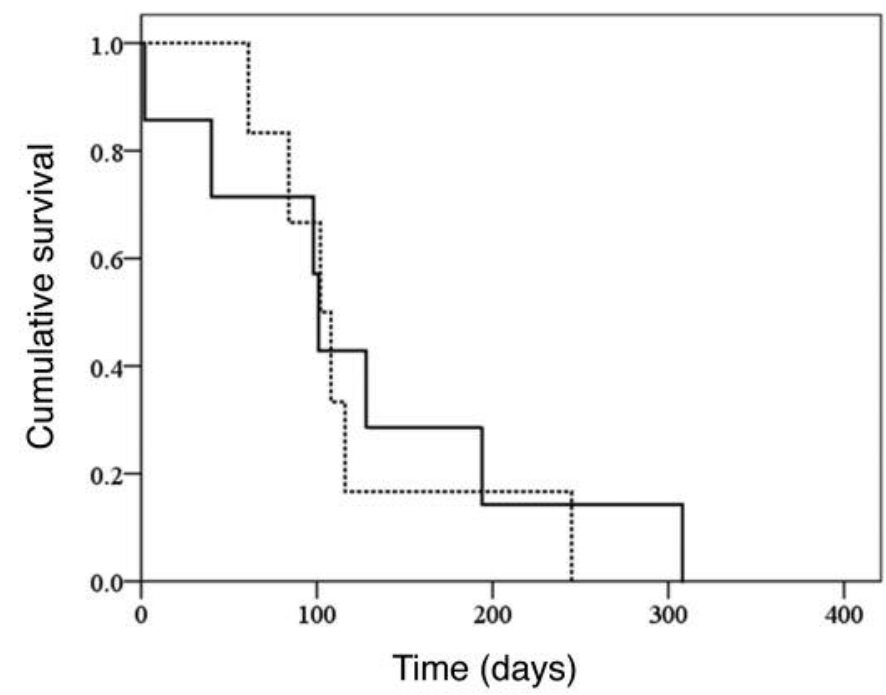

B

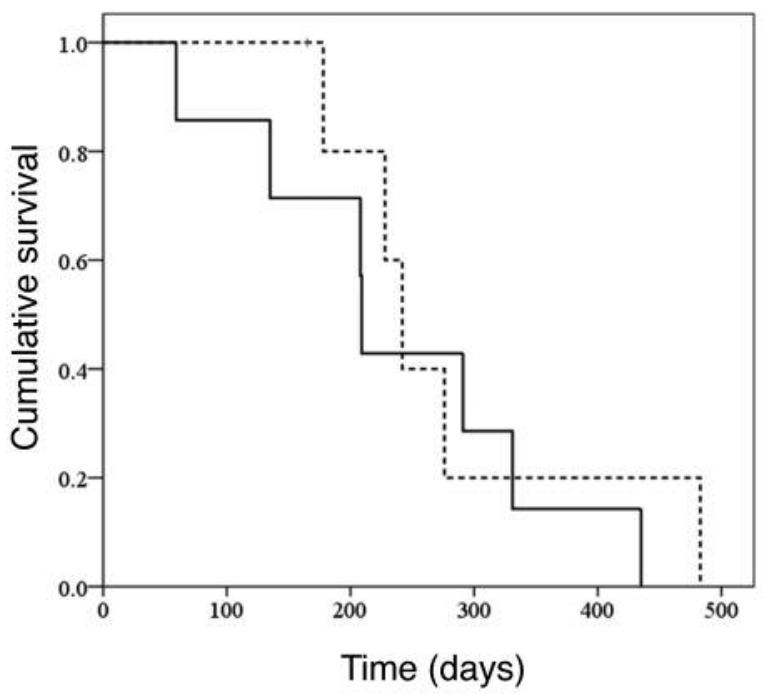

Figure 2. Kaplan-Meier curves of PFS (A) and OS $(B)$ according to patient group. Solid lines indicate the patients who showed tumor shrinkage of $20 \%$ or more at the initial anti-EGFR therapy $(n=7)$. Dotted lines indicate the patients who showed tumor shrinkage of less than $20 \%$ at the initial anti-EGFR therapy $(n=6)$.

\section{Discussion}

The present study examined survival following the readministration of anti-EGFR antibody for chemotherapyrefractory mCRC in clinical practice. The median PFS and the median OS were 102 days (3.4 months) and 228 days (7.6 months), respectively. A recent randomized phase III clinical study determining the efficacy of trifluridine/tipiracil hydrochloride as salvage line chemotherapy for mCRC, reported the median PFS and OS as 2.0 and 7.1 months, respectively (15), results comparable to those presented here. Three patients out of 13 patients in our study showed $>15 \%$ tumor shrinkage with the readministration of an anti-EGFR antibody. Among these three patients, two showed tumor 
A
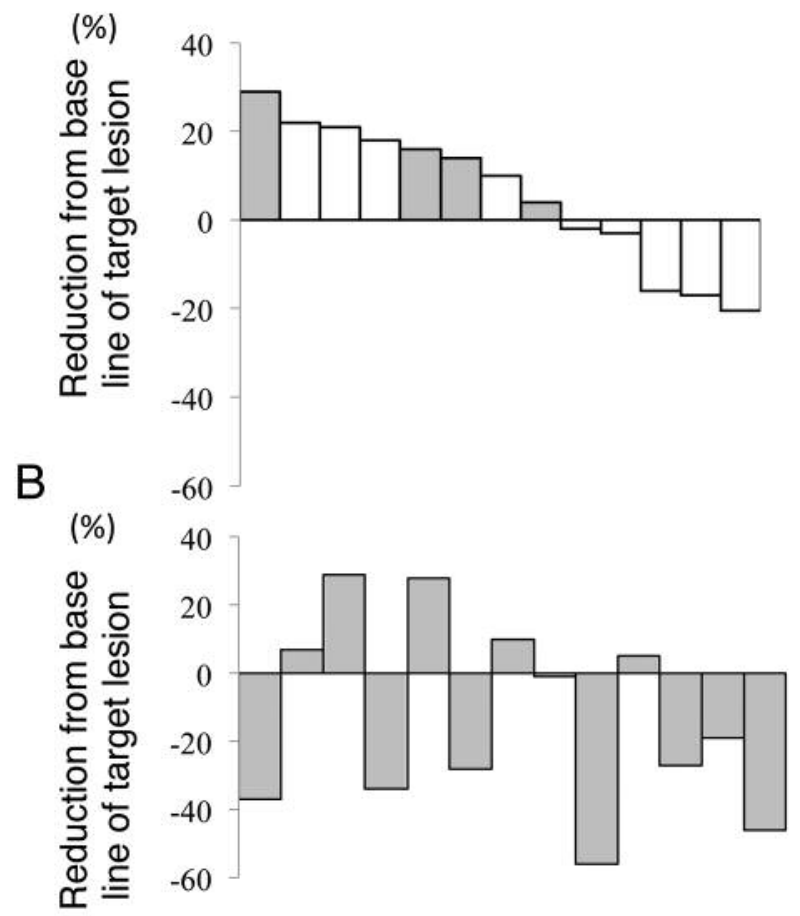

Figure 3. Waterfall plot of tumor growth in each patient. Reduction from base line of target lesion in the readministration of anti-EGFR antibody (A) and in the prior anti-EGFR therapy (B) of each patient. Upward of the vertical axis indicates increasing of tumor size. White columns indicate the patients of whom readministration of the switched anti$E G F R$ antibody from the prior therapy, and grey columns indicate the patients of whom readministration of the same anti-EGFR antibody as that in prior therapy.

shrinkage in response to prior anti-EGFR therapy, and the interval between prior anti-EGFR therapy and readministration was longer than three months in both cases (129 and 301 days). In the other patient, panitumumab in combination with FOLFOX was administrated, thus a therapeutic effect of oxaliplatin may also have played a role in the observed tumor response. These findings suggest that readministration of anti-EGFR antibody has the potential for survival benefits in certain patient populations.

Several studies have been conducted to clarify the clinical efficacy of anti-EGFR antibody readministration in mCRC after previous treatment failure. Most of these studies examined relatively small numbers of patients with variable backgrounds. They demonstrated that, in the best cases, readministration of anti-EGFR antibody could achieve stable disease or minor clinical responses. Among them, a randomized phase II clinical study (the CAPRI-GOIM study) assessed the efficacy of the continuous use of anti-EGFR
Table III. Adverse events.

\begin{tabular}{lrrcc}
\hline Event & $\begin{array}{c}\text { No. with } \\
\text { any grade }\end{array}$ & $\%$ & $\begin{array}{c}\text { No. with } \\
\text { grade } \geq 3\end{array}$ & $\%$ \\
\hline Leukopenia & 5 & 38 & 0 & 0 \\
Neutropenia & 1 & 8 & 0 & 0 \\
Anemia & 12 & 92 & 0 & 0 \\
Thrombocytopenia & 1 & 8 & 1 & 8 \\
Paronychia & 0 & 0 & 1 & 8 \\
Rash acneiform & 12 & 92 & 0 & 0 \\
Dry skin & 5 & 38 & 0 & 0 \\
Peripheral sensory neuropathy & 1 & 8 & 1 & 8 \\
Ileus & 0 & 0 & 1 & 8 \\
Constipation & 0 & 0 & 0 & 0 \\
Oral mucositis & 1 & 8 & 0 & 0 \\
Hand-Foot syndrome & 1 & 8 & 0 & 0 \\
\hline
\end{tabular}

therapy after the failure of prior therapy involving an antiEGFR antibody (16). In this study, $340 K R A S$ exon 2 wildtype mCRC patients were enrolled, and of these, 153 patients who showed stable disease or better responses following first-line treatment with FOLFIRI plus cetuximab, were randomly assigned to a FOLFOX plus cetuximab treatment group or a FOLFOX only treatment group for subsequent therapy. Whereas no clinical advantage of the continuation of cetuximab was observed when considering the total cohort (median PFS 6.4 and 4.5 months for the two treatment groups, respectively; hazard ratio (HR) 0.81 , $p=0.19$ ), a significantly better median PFS for the cetuximab-continuing group was observed in patients that were shown to be wildtype for the KRAS, NRAS, BRAF and PIK3CA genes (median PFS 6.9 and 5.3 months, respectively; HR $0.56, p=0.025)$. The clinical benefit for such selected patient population might be associated with the addiction of tumor cells for the EGFR-signaling pathway, but other potential molecular mechanisms contributing to the acquired resistance mechanisms against anti-EGFR therapy were not clarified. However, these findings suggest that continuous use of anti-EGFR antibody after the failure of prior anti-EGFR therapy might not be appropriate for all patients, and that it may be better to use anti-angiogenic agents in certain cases, with the decision informed by molecular profiling.

The molecular mechanisms of acquired resistance to antiEGFR therapy have been reported to include: (a) gene amplification of the ERBB2 gene or the MET gene (17-19); (b) the acquisition of RAS gene mutations $(20,21)$; and (c) the acquisition of alterations in the extracellular domain of the EGFR protein $(22,23)$. Such genetic alterations may potentially be present but undetectable in the tumor prior to anti-EGFR therapy. Switching of cetuximab utilized in the 
A

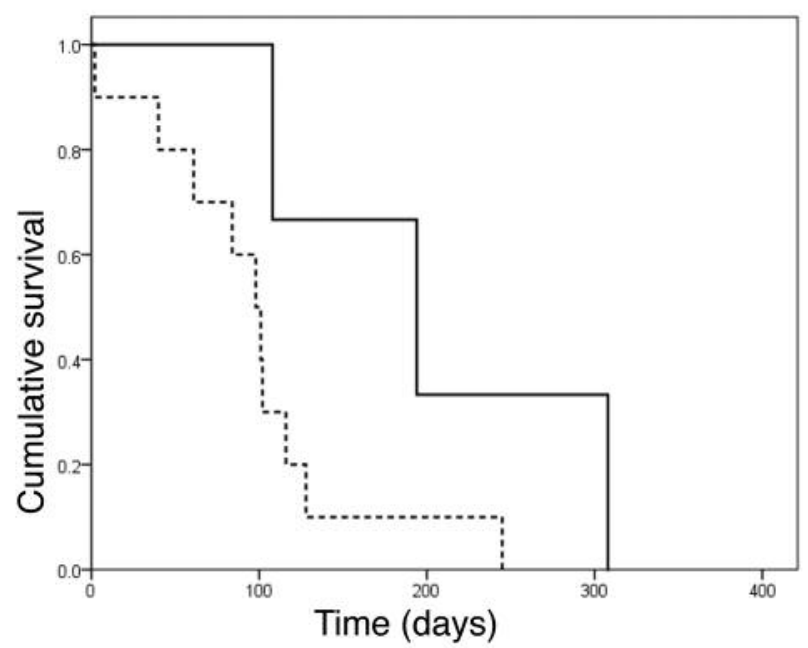

B

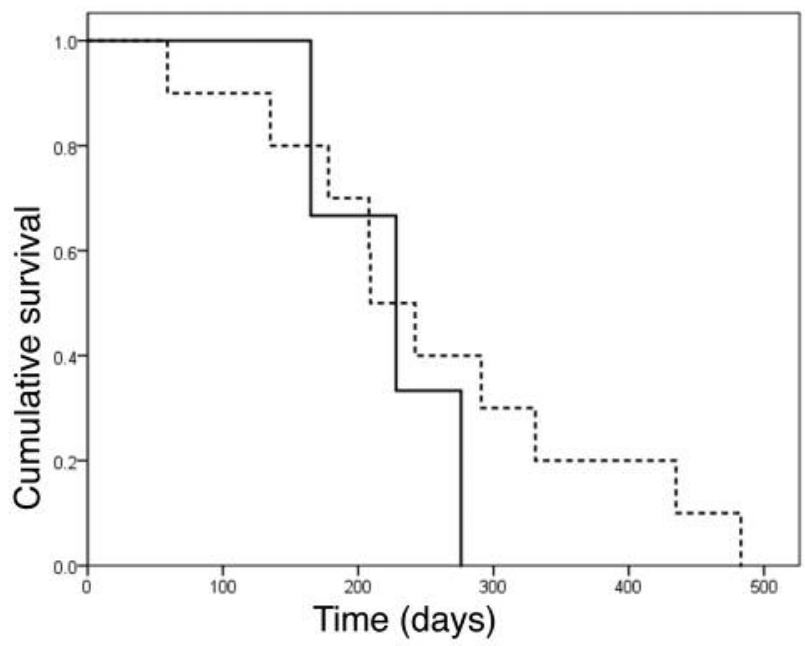

Figure 4. Kaplan-Meier curves of PFS $(A)$ and $O S(B)$ according to patient group. Solid lines indicate the patients of whom readministration of anti-EGFR antibody was performed after 90 days or more of interval $(n=3)$. Dotted lines indicate the patients of whom readministration of antiEGFR antibody after the interval of free of anti-EGFR antibody less than 90 days $(N=10)$.

A

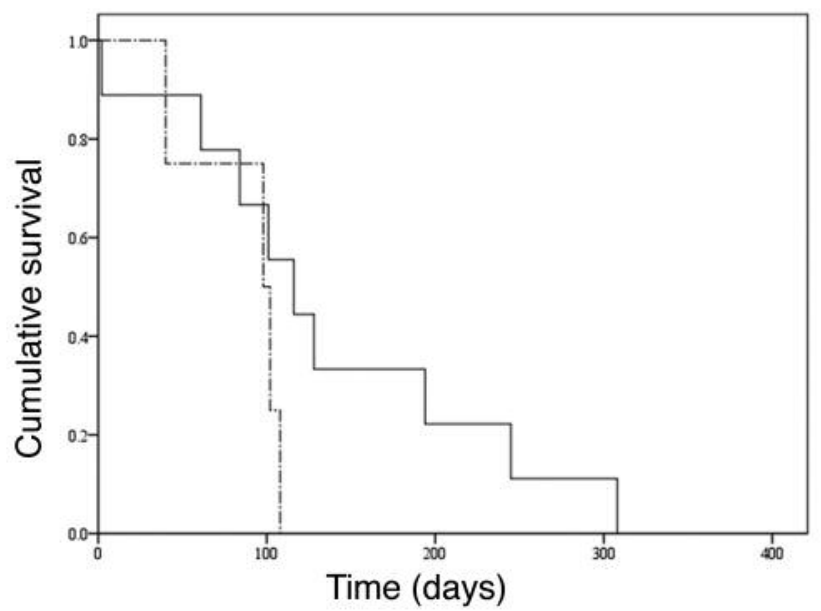

B

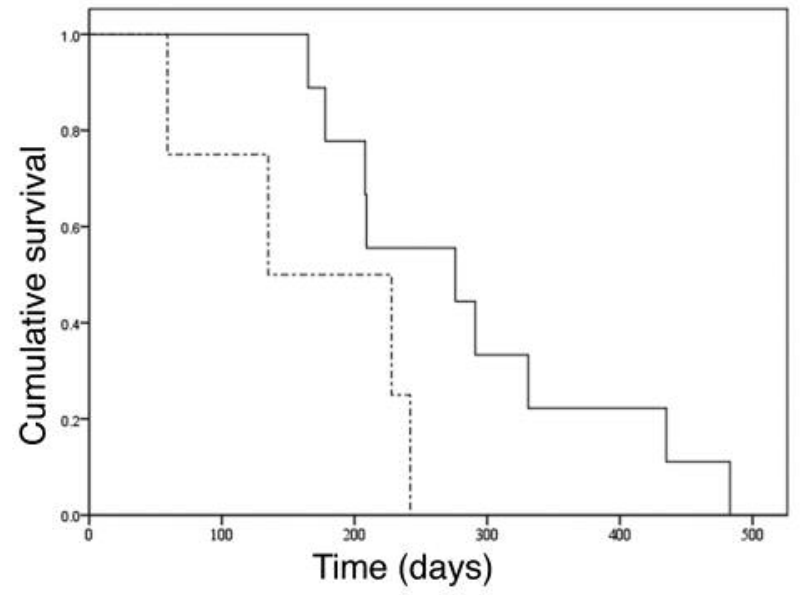

Figure 5. Kaplan-Meier curves of PFS (A) and OS (B) according to patient group. Solid lines indicate the patients of whom readministration of the switched anti-EGFR antibody from the prior therapy $(n=9)$. Dotted lines indicate the patient of whom readministration of the same anti-EGFR antibody as that in the prior therapy $(n=4)$.

prior therapy to panitumumab might possibly be effective in the readministration because EGFR S492R mutation could confer cetuximab resistance (22). However, only two patients (No. 11, 12) among seven patients, who switched from cetuximab to panitumumab, showed apparent tumor shrinkage in this study, suggesting impact of anti-EGFR antibody switching in the readministration remained to be clarified. Recent analyses of circulating tumor DNA have demonstrated that tumors are composed of genetically heterogeneous cellular populations and that the dominant tumor cell population may change during anti-EGFR therapy $(24,25)$. Thus, while therapy-resistant tumor cells may 
become dominant during initial treatment, it is possible for sensitive tumor clones to become dominant again once treatment ceases. This could be one of the possible explanations why a longer anti-EGFR therapy-free period might contribute better survival outcomes in the readministration of anti-EGFR therapy.

Santini et al. demonstrated the efficacy of cetuximab readministration after a drug-free interval for $39 \mathrm{mCRC}$ patients who responded to prior irinotecan plus cetuximab therapy, in a phase II study (26). Surprisingly, the overall response rate was 54\% and the median PFS was 6.6 months. The median interval between the last cycle of initial antiEGFR therapy and the first cycle of cetuximab retreatment was 6 months. However, the interval times for individual patients, especially for those that responded well during readministration, was not provided. In another study (the PANERB study), the efficacy of readministration of panitumumab for $106 \mathrm{mCRC}$ patients was prospectively determined. The response rate following readministration was reported to be $18 \%$ overall, but $31 \%$ in patients who responded to prior anti-EGFR therapy (27). Finally, Wadlow et al. reported that panitumumab achieved stable disease in $45 \%$ of KRAS-wildtype mCRC patients (9/20 cases) after progression on prior cetuximab therapy (28), and no anticetuximab antibody, which could potentially interfere cetuximab activity, after the cetuximab therapy was detected in these patients. These findings compare favorably to our own observation of an overall response rate of $23 \%$ for the readministration of anti-EGFR antibody, regardless of prior responsiveness to anti-EGFR therapy, but noting that patients with prior anti-EGFR responses tended to exhibit efficacy with readministration. Additionally, readministrationresponding patients may benefit from longer intervals between prior and readministration anti-EGFR therapy, however no comparative analyses of the anti-EGFR therapyfree period have been performed in previous reports. In the present study, we found that patients who were readministered anti-EGFR antibody following an interval of more than 90 days had more favorable outcomes than those for whom the interval was less than 90 days. These data suggest that the clinical application of anti-EGFR readministration therapy should take into account the interval between treatments, and that the molecular mechanisms of anti-EGFR resistance might be released during the treatmentfree interval.

The new anticancer drugs regorafenib and trifluridine/ tipiracil hydrochloride are now effective therapeutic options for salvage chemotherapy of mCRC $(15,29)$. Regorafenib showed a survival benefit over placebo in a phase III clinical study for mCRC, with a median OS of 6.4 and 5.0 months, respectively (29). Trifluridine/tipiracil hydrochloride also showed clinical benefit, with a median OS of 7.1 months compared to 5.3 months for the placebo group (15). It should be noted that the patients examined in the present study did not receive either of these drugs prior to anti-EGFR antibody readministration, and thus it is difficult to compare the survival advantage of the readministration of anti-EGFR antibody and that of the administration of these two new agents. However, the most appropriate sequential treatment strategy for salvage chemotherapy with these new drugs still remains to be clarified.

A limitation of the present study is that we examined only a small cohort of mCRC patients, and both the prior and subsequent anti-EGFR therapy combinations varied. However, our survival results are consistent with those observed in previous clinical studies. In addition, the observation that a longer interval between anti-EGFR therapies and switching of antibody may provide a survival advantage in the readministration of anti-EGFR antibody, is valuable information for the design of salvage-line therapy for mCRC. Further clinical studies, examining the most appropriate sequential chemotherapy design for the readministration of anti-EGFR antibody in combination with new drugs, is now warranted.

\section{Conflicts of Interest}

Baba E and Esaki T received research grants from Takeda Pharm and Merck Serono.

\section{Acknowledgements}

The Authors would like to thank the patients and their families for participating in this study, and the medical staff for their respective contributions to the treatment of patients.

\section{References}

1 Global Burden of Disease Cancer Collaboration, Fitzmaurice C, Allen C, Barber RM et al: Global, regional, and national cancer incidence, mortality, years of life lost, years lived with disability, and disability-adjusted life-years for 32 cancer groups, 1990 to 2015: A systematic analysis for the global burden of disease study. JAMA Oncol 3: 524-548, 2017.

2 Cancer Registry and Statistics. Cancer Information Service, National Cancer Center, Japan. http://ganjoho.jp/reg_stat/ index.html

3 Saltz LB, Clarke S, Diaz-Rubio E, Scheithauer W, Figer A, Wong R, Koski S, Lichinitser M, Yang TS, Rivera F, Couture F, Sirzen $\mathrm{F}$ and Cassidy $\mathrm{J}$ : Bevacizumab in combination with oxaliplatin-based chemotherapy as first-line therapy in metastatic colorectal cancer: a randomized phase III study. J Clin Oncol 26: 2013-2019, 2008.

4 Tabernero J, Yoshino T, Cohn AL, Obermannova R, Bodoky G, Garcia-Carbonero R, Ciuleanu TE, Portnoy DC, Van Cutsem E, Grothey A, Prausová J, Garcia-Alfonso P, Yamazaki K, Clingan PR, Lonardi S, Kim TW, Simms L, Chang SC and Nasroulah F: Ramucirumab versus placebo in combination with second-line FOLFIRI in patients with metastatic colorectal carcinoma that 
progressed during or after first-line therapy with bevacizumab, oxaliplatin, and a fluoropyrimidine (RAISE): a randomised, double-blind, multicentre, phase 3 study. Lancet Oncol 16: 499508, 2015.

5 Van Cutsem E, Lenz HJ, Köhne CH, Heinemann V, Tejpar S, Melezínek I, Beier F, Stroh C, Rougier P, van Krieken JH and Ciardiello F: Fluorouracil, leucovorin, and irinotecan plus cetuximab treatment and RAS mutations in colorectal cancer. J Clin Oncol 33: 692-700, 2015.

6 Douillard JY, Oliner KS, Siena S, Tabernero J, Burkes R, Barugel M, Humblet Y, Bodoky G, Cunningham D, Jassem J, Rivera F, Kocákova I, Ruff P, Błasińska-Morawiec M, Šmakal M, Canon JL, Rother M, Williams R, Rong A, Wiezorek J, Sidhu R and Patterson SD: Panitumumab-FOLFOX4 treatment and RAS mutations in colorectal cancer. N Engl J Med 369: 1023-1034, 2013.

7 Peeters M, Price TJ, Cervantes A, Sobrero AF, Ducreux M, Hotko Y, André T, Chan E, Lordick F, Punt CJ, Strickland AH, Wilson G, Ciuleanu TE, Roman L, Van Cutsem E, Tian Y and Sidhu R: Final results from a randomized phase 3 study of FOLFIRI+/-panitumumab for second-line treatment of metastatic colorectal cancer. Ann Oncol 25: 107-16, 2014.

8 Jonker DJ, O'Callaghan CJ, Karapetis CS, Zalcberg JR, Tu D, Au HJ, Berry SR, Krahn M, Price T, Simes RJ, Tebbutt NC, van Hazel G, Wierzbicki R, Langer C and Moore MJ: Cetuximab for the treatment of colorectal cancer. N Engl J Med 357: 20402048, 2007.

9 Amado RG, Wolf M, Peeters M, Van Cutsem E, Siena S, Freeman DJ, Juan T, Sikorski R, Suggs S, Radinsky R, Patterson $\mathrm{SD}$ and Chang DD: Wild-type KRAS is required for panitumumab efficacy in patients with metastatic colorectal cancer. J Clin Oncol 26: 1626-1634, 2008

10 Baselga J: Treatment of HER2-overexpressing breast cancer. Ann Oncol 21(Suppl 7): vii36-40, 2010.

11 Bennouna J, Sastre J, Arnold D, Österlund P, Greil R, Van Cutsem E, von Moos R, Viéitez JM, Bouché O, Borg C, Steffens CC, Alonso-Orduña V, Schlichting C, Reyes-Rivera I, Bendahmane B, André T and Kubicka S; ML18147 Study Investigators: Continuation of bevacizumab after first progression in metastatic colorectal cancer (ML18147): a randomised phase 3 trial. Lancet Oncol 14: 29-37, 2013.

12 Misale S, Di Nicolantonio F, Sartore-Bianchi A, Siena S and Bardelli A: Resistance to anti-EGFR therapy in colorectal cancer: from heterogeneity to convergent evolution. Cancer Discov 4: 1269-1280, 2014.

13 Eisenhauer EA, Therasse P, Bogaerts J, Schwartz LH, Sargent D, Ford R, Dancey J, Arbuck S, Gwyther S, Mooney M, Rubinstein L, Shankar L, Dodd L, Kaplan R, Lacombe D and Verweij J: New response evaluation criteria in solid tumours: revised RECIST guideline (version 1.1). Eur J Cancer 45: 228247, 2009.

14 National Cancer Institute: Common Terminology Criteria for Adverse Events (CTCAE), version 4.0. http://evs.nci.nih.gov/ftp1/ CTCAE/CTCAE_4.03_2010-06-14_QuickReference_5x7.pdf.

15 Mayer RJ, Van Cutsem E, Falcone A, Yoshino T, GarciaCarbonero R, Mizunuma N, Yamazaki K, Shimada Y, Tabernero J, Komatsu Y, Sobrero A, Boucher E, Peeters M, Tran B, Lenz HJ, Zaniboni A, Hochster H, Cleary JM, Prenen H, Benedetti F, Mizuguchi H, Makris L, Ito M and Ohtsu A; RECOURSE Study Group: Randomized trial of TAS-102 for refractory metastatic colorectal cancer. N Engl J Med 372: 1909-1919, 2015.
16 Ciardiello F, Normanno N, Martinelli E, Troiani T, Pisconti S, Cardone C, Nappi A, Bordonaro AR, Rachiglio M, Lambiase M, Latiano TP, Modoni G, Cordio S, Giuliani F, Biglietto M, Montesarchio V, Barone C, Tonini G, Cinieri S, Febbraro A, Rizzi D, De Vita F, Orditura M, Colucci G, Maiello E, CAPRIGOIM Investigators and CAPRI-GOIM investigators: Cetuximab continuation after first progression in metastatic colorectal cancer (CAPRI-GOIM): a randomized phase II trial of FOLFOX plus cetuximab versus FOLFOX. Ann Oncol 27: 1055-1061, 2016

17 Yonesaka K, Zejnullahu K, Okamoto I, Satoh T, Cappuzzo F, Souglakos J, Ercan D, Rogers A, Roncalli M, Takeda M, Fujisaka Y, Philips J, Shimizu T, Maenishi O, Cho Y, Sun J, Destro A, Taira K, Takeda K, Okabe T, Swanson J, Itoh H, Takada M, Lifshits E, Okuno K, Engelman JA, Shivdasani RA, Nishio K, Fukuoka M, Varella-Garcia M, Nakagawa K and Jänne PA: Activation of ERBB2 signaling causes resistance to the EGFR-directed therapeutic antibody cetuximab. Sci Transl Med 3: 99ra86, 2011

18 Bertotti A, Migliardi G, Galimi F, Sassi F, Torti D, Isella C, Corà D, Di Nicolantonio F, Buscarino M, Petti C, Ribero D, Russolillo N, Muratore A, Massucco P, Pisacane A, Molinaro L, Valtorta E, Sartore-Bianchi A, Risio M, Capussotti L, Gambacorta M, Siena S, Medico E, Sapino A, Marsoni S, Comoglio PM, Bardelli A and Trusolino L: A molecularly annotated platform of patient-derived xenografts ("xenopatients") identifies HER2 as an effective therapeutic target in cetuximab-resistant colorectal cancer. Cancer Discov 1: 508-523, 2011.

19 Bardelli A, Corso S, Bertotti A, Hobor S, Valtorta E, Siravegna G, Sartore-Bianchi A, Scala E, Cassingena A, Zecchin D, Apicella M, Migliardi G, Galimi F, Lauricella C, Zanon C, Perera T, Veronese S, Corti G, Amatu A, Gambacorta M, Diaz LA Jr, Sausen M, Velculescu VE, Comoglio P, Trusolino L, Di Nicolantonio F, Giordano S and Siena S: Amplification of the MET receptor drives resistance to anti-EGFR therapies in colorectal cancer. Cancer Discov 3: 658-673, 2013.

20 Morelli MP, Overman MJ, Dasari A, Kazmi SM, Mazard T, Vilar E, Morris VK, Lee MS, Herron D, Eng C, Morris J, Kee BK, Janku F, Deaton FL, Garrett C, Maru D, Diehl F, Angenendt P and Kopetz S: Characterizing the patterns of clonal selection in circulating tumor DNA from patients with colorectal cancer refractory to anti-EGFR treatment. Ann Oncol 26: 731-736, 2015.

21 Siravegna G, Mussolin B, Buscarino M, Corti G, Cassingena A, Crisafulli G, Ponzetti A, Cremolini C, Amatu A, Lauricella C, Lamba S, Hobor S, Avallone A, Valtorta E, Rospo G, Medico E, Motta V, Antoniotti C, Tatangelo F, Bellosillo B, Veronese S, Budillon A, Montagut C, Racca P, Marsoni S, Falcone A, Corcoran RB, Di Nicolantonio F, Loupakis F, Siena S, SartoreBianchi A and Bardelli A: Clonal evolution and resistance to EGFR blockade in the blood of colorectal cancer patients. Nat Med 21: 795-801, 2015.

22 Montagut C, Dalmases A, Bellosillo B, Crespo M, Pairet S, Iglesias M, Salido M, Gallen M, Marsters S, Tsai SP, Minoche A, Seshagiri S, Serrano S, Himmelbauer H, Bellmunt J, Rovira A, Settleman J, Bosch F and Albanell J: Identification of a mutation in the extracellular domain of the Epidermal Growth Factor Receptor conferring cetuximab resistance in colorectal cancer. Nat Med 18: 221-223, 2012.

23 Price TJ, Newhall K, Peeters M, Kim TW, Li J, Cascinu S, Ruff $\mathrm{P}$, Suresh AV, Thomas A, Tijulandin S, Boedigheimer M, Zhang 
K, Sidhu R and Murugappan S: Prevalence and outcomes of patients (pts) with EGFR S492R ectodomain mutations in ASPECCT: Panitumumab (pmab) vs. cetuximab ( $\mathrm{cmab}$ ) in pts with chemorefractory wild-type KRAS exon 2 metastatic colorectal cancer (mCRC). J Clin Oncol 33(suppl 3): abstr 740, 2015.

24 Diaz LA Jr, Williams RT, Wu J, Kinde I, Hecht JR, Berlin J, Allen B, Bozic I, Reiter JG, Nowak MA, Kinzler KW, Oliner $\mathrm{KS}$ and Vogelstein B: The molecular evolution of acquired resistance to targeted EGFR blockade in colorectal cancers. Nature 486: 537-540, 2012.

25 Misale S, Yaeger R, Hobor S, Scala E, Janakiraman M, Liska D, Valtorta E, Schiavo R, Buscarino M, Siravegna G, Bencardino K, Cercek A, Chen CT, Veronese S, Zanon C, Sartore-Bianchi A, Gambacorta M, Gallicchio M, Vakiani E, Boscaro V, Medico E, Weiser M, Siena S, Di Nicolantonio F, Solit D and Bardelli A: Emergence of KRAS mutations and acquired resistance to anti-EGFR therapy in colorectal cancer. Nature 486: 532-536, 2012.

26 Santini D, Vincenzi B, Addeo R, Garufi C, Masi G, Scartozzi M, Mancuso A, Frezza AM, Venditti O, Imperatori M, Schiavon G, Bronte G, Cicero G, Recine F, Maiello E, Cascinu S, Russo A, Falcone A and Tonini G: Cetuximab rechallenge in metastatic colorectal cancer patients: how to come away from acquired resistance? Ann Oncol 23: 2313-2318, 2012.
27 Metges J, Raoul J, Achour N, Capitain O, Gourlaouen A, Ramée J, Egreteau J, Douilard J, Traoré S and Grudé F: PANERB study: panitumumab after cetuximab-based regimen failure. J Clin Oncol 28, 2010. doi: 10.1200/jco.2010.28.15_suppl.e14000 [Epub ahead of print]

28 Wadlow RC, Hezel AF, Abrams TA, Blaszkowsky LS, Fuchs CS, Kulke MH, Kwak EL, Meyerhardt JA, Ryan DP, Szymonifka J, Wolpin BM, Zhu AX and Clark JW: Panitumumab in patients with KRAS wild-type colorectal cancer after progression on cetuximab. Oncologist 17: 14, 2012.

29 Grothey A, Van Cutsem E, Sobrero A, Siena S, Falcone A, Ychou M, Humblet Y, Bouché O, Mineur L, Barone C, Adenis A, Tabernero J, Yoshino T, Lenz HJ, Goldberg RM, Sargent DJ, Cihon F, Cupit L, Wagner A and Laurent D; CORRECT Study Group: Regorafenib monotherapy for previously treated metastatic colorectal cancer (CORRECT): an international, multicentre, randomised, placebo-controlled, phase 3 trial. Lancet Oncol 381: 303-312, 2013.

Received June 9, 2017

Revised July 3, 2017

Accepted July 4, 2017 